\title{
Clío en el exilio*
}

François Dosse

ESPACES TEMPS

El autor discute la relación entre historia y posmodernidad en el pensamiento europeo contemporáneo.

$\mathrm{E}$

1 campo de la historia no lo trabajan sólo los historiadores sino que está en extremo expuesto a los azares de la coyuntura intelectual. Considerado primero como el lugar de la razón realizada en nombre de una teleología finalista y después cogido entre las redes de un desorden sublunar que vuelve caduca la inteligibilidad, el concepto de historia ha sido seriamente socavado por el programa estructuralista, que ha atacado los dos diques constitutivos de su identidad: ciencia del cambio, ciencia de síntesis.

* Publicado en L'bomme et la socítè núms. 95 96, 1990, pp. 103-118. Traducción de Ena Lastra.

\section{UNA POSHISTORIA}

En el umbral del siglo xx Europa comienza a ver resquebrajarse los basamentos del evolucionismo del siglo XIX. Herederas de la ilustración, de la Aufkläruno, las ciencias sociales vivían entonces la época dorada de los avances hacia la edad de la perfección, de la razón triunfante. Los partidarios del inmovilismo, o los del cambio, sólo se entienden dentro del esquema global de evolución de un progreso continuo. Ya se trate de Saint Simon, Spencer, Comte o Marx, se ve perfilarse en el horizonte de la humanidad entera la sucesión: en Comte, del estado teológico, luego el metafísico, 
hasta el positivo; en Marx, el paso del esclavismo a la servidumbre, al capitalismo, para terminar en el socialismo. Estas certezas de construir desde la perspectiva del progreso van a tropezar con lo real trágico de un siglo Xx que no ha terminado de dar sorpresas al eurocentrismo: En cada una de sus conmociones, Europa ha llegado a enterrar la idea misma de un porvenir de ruptura; éste se ha convertido en una dilatación del presente, una presentificación del pasado y un nuevo modo de relación con la historicidad en que el presente no se piensa más como anticipación del porvenir sino como campo de un posible reciclaje del pasado, según el modo genealógico. El porvenir se disuelve y el presente estacionario permite que el pasado no se aleje más: "La diferencia es un porvenir que no ahonda más en el presente, he aquí que se vuelve hacia atrás, al revés". ${ }^{1}$ Es una relación entre pasado y presente que se instituye cuando no hay razón para buscar en ella lo que permite construir otro devenir, cuando el porvenir está encerrado, pegado a un equilibrio presente llamado a repetirse indefinidamente. La moda de lo nuevo, escenografia publicitaria de lo cotidiano, permite diluir aún más toda eventualidad de una futura alteridad. Sobre la base del rechazo de toda teleología histórica, de todo sentido asignado a la historia de la humanidad, se recobran las bellezas perdidas de "ese mundo que hemos perdido", de una edad media magnificada como lugar de una alteridad ligada a la búsqueda de las raíces de la identidad. Es en el contexto de este descentramiento, de esta dislocación de la cultura europea, de deconstrucción de la metafísica, que una conciencia nueva, etnológica, se impone y substituye a una conciencia

\footnotetext{
${ }^{1}$ Torres, Déjà, 1986, p. 142.
}

histórica. El Occidente se pregunta por su opuesto, por las maneras de ser del otro escenario, invisible, lugar cuya presencia es revelada por su ausencia misma. Detrás de la conciencia, Freud descubre las leyes del inconsciente; detrás del desorden de nuestra sociedad, Durheim descifra el inconsciente de nuestras prácticas colectivas. La posmodernidad se construye entonces al buscar los mecanismos subyacentes, se concibe como la deconstructora del humanismo calificado de edad media por Foucault, y se apoya en esta revolución epistemológica-triunfante en los años sesenta-para glorificarla: "El estructuralismo no es un método nuevo, es la conciencia despierta e inquieta del saber moderno."2

El provincianismo de la razón occidental, el descubrimiento de la irreductibilidad de la resistencia a otras lógicas, a la pluralidad cultural, nutrieron un pesimismo fundamental, una especie de teología negativa. Las decepciones del racionalismo occidental corrieron a contrapelo del racionalismo optimista para caer en una especie de nihilismo, de pensamiento límite, en las fronteras de la razón y la no razón. Situación compleja porque mezcla al mismo tiempo una idiosincrasia personal hecha de desilusión, de rechazo, pero marcada por el punto de partida rechazado. La teorización de la incapacidad del hombre para tener dominio sobre su historia colectiva o personal, el acento puesto sobre su calidad de incompleto, la pavana difunta de la razón occidental, anuncian al mismo tiempo un trabajo más riguroso, más lúcido de la misma razón occidental. Es ella la que opera en la obra de LéviStrauss cuando exhuma las sociedades primitivas, es ella la que permite a Lacan curar a sus pacientes. Incluso es ella la

\footnotetext{
${ }^{2}$ Foucault, Mots, 1966, p. 221.
} 


\section{SECUENCIG}

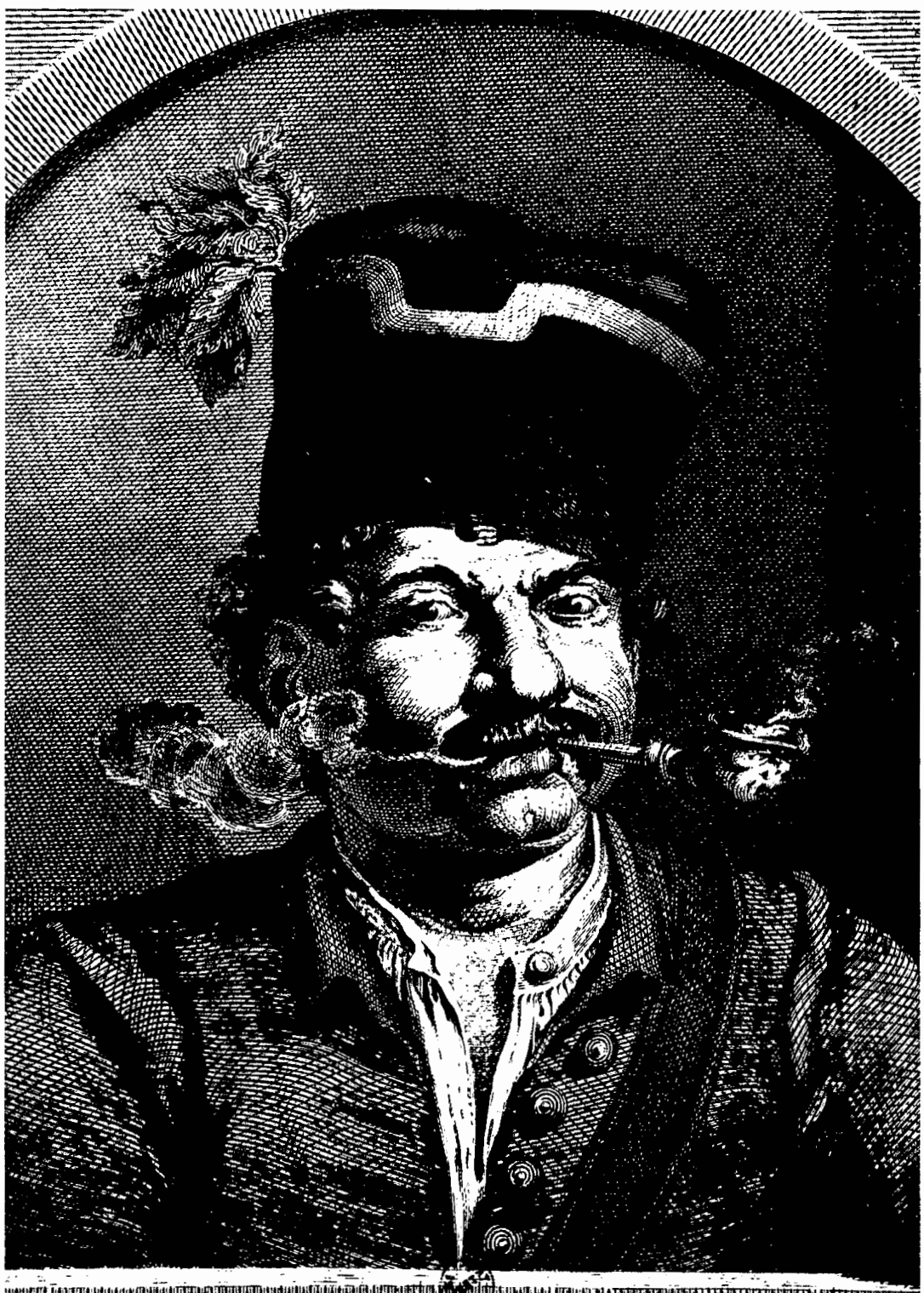


que permite a Foucault ponerse del lado de los olvidados, de los rechazados, de los prisioneros. Artimaña de una razón que trabaja de por sí para su propio descentramiento.

De las rupturas, el siglo $\mathrm{xx}$ indujo un pesimismo básico en relación con la historia y el advenimiento de una era llamada posmoderna. Con Jean-François Lyotard se puede poner fecha a la ruptura de tajo y definitiva del evolucionismo occidental en $1943,{ }^{3}$ momento de la solución final, volcamiento radical en el horror. Será necesario pensar en lo sucesivo según Dachau, según Auschwitz, como ha dicho Adorno. Al transformarse en rodillo aplanador, en máquina de muerte a escala planetaria, la modernidad tecnológica se ve aquejada de negatividad y apresada por la ideología de la sospecha. A esto se agrega el descubrimiento de lo que hay detrás de la cortina de hierro, bajo lo que se daba como modelo y que se revela como la realidad del totalitarismo, bajo la razón, sus ardides implacables que vuelven a poner la tapa a las esperanzas de creación de un mundo mejor, y eso constata una necesaria discontinuidad: "Nosotros debemos recomenzar de cero. ${ }^{n 4}$ Una cierta mirada ingenua a la exaltación del progreso continuo de la libertad y de la lu. cidez humana ya no es posible. El humanismo, en el sentido de un hombre dueño de su destino, perfectible, marchando en línea recta hacia la perfección, ya no es admisible. La visión de los mañanas que cantan es substituida por la aproximación utópica de cambios parciales en los que es necesario definir los límites de lo posible. 1956 con su cortejo de desilusiones, de Budapest a Alejandría,

\footnotetext{
${ }^{3}$ Lyotard, Magazine, núm. 225, diciembre de 1985, p. 43.

"Foucault, "Folter", 1977.
}

pasando por Argel, interrumpió los cantos de liberación y de una cierta esperanza colectiva. A mediados de este siglo suenan y truenan contra la voz del amo, la fuerza de las resistencias al cambio, la invariancia de la regla, la prevalencia del código. Durante toda una generación, la esperanza revolucionaria -desde el punto de vista de las fuerzas opresivas- es devuelta a la condición de mitología, reducida a fantasma y confinada, rechazada como mito del siglo XXX. Estas grandes transiciones en el límite, que invocaron con sus votos los intelectuales, sufren una erosión irreversible en una sociedad occidental que no se piensa más como surgiendo de una historia apasionada sino que parece copiar a las sociedades primitivas para privilegiar una relación fría con una temporalidad que se ve clavada al suelo, en la inmovilidad.

La escatología revolucionaria se deshace en la muela de las resistencias, bloqueos e inercias propias de nuestra sociedad. Al descrédito que afecta al compromiso y al voluntarismo político corresponde, en el plano teórico, un descrédito similar que toca esta vez a todo lo que pertenece a la historia. Es a partir de esta negación de la historicidad, de la búsqueda de los orígenes, de la génesis, de toda reflexión sobre los ritmos temporales, que va a combatir y a expandirse el paradigma estructuralista; que a su vez va a paralizar el movimiento, va a enfriar la historia, va a antropologizarla para después deconstruirla. La fascinación de un Occidente que rompe con su historicidad por medio del modo de vida inmutable de los nambikwaras restituido por Lévi-Strauss, nos revela a mediados de los años cincuenta que Occidente entra en la era de la posmodernidad. La idea misma de progreso está sometida a la desinfección, en todo caso como fenómenounificador; el progreso se pluraliza, 
deja de ser la fuerza motriz de la evolución social, sin negar ciertos avances que noparticipan ya enuna problematización global de la sociedad. La deconstrucción está en la base de una verdadera revolución intelectual que inaugura el estructuralismo, especialmente en la antropología, con la idea de la equivalencia de la especie humana. Es el tránsito, decisivo de Lévi-Bruhl a Lévi-Strauss; este último muestra que, más allá de las latitudes, de la pluralidad de los modos de ser y de pensar, todas las sociedades humanas son expresiones plenas de la humanidad sin valor jerárquico. Este aspecto de la revolución estructuralista permanece insuperable e inaugura una nueva percepción del mundo que traza una línea de igualdad entre todas las formas de organización social. A partir de esta nueva visión ya no hay más planos superiores e inferiores, ni estadios anteriores y posteriores. Así, el estructuralismo contribuyó grandemente a poner en crisis la idea de progreso. Por supuesto, de la relatividad al relativismo el paso será dado rápidamente sin duda, pero sea cual fuere la posición defendida, la aprehensión del otro como manifestación parcial de lo universal humano provoca la salida del esquema evolucionista del siglo XIX. Las ciencias humanas han substituido entonces la conciencia de una Europa modelo, vanguardista en la marcha de la humanidad, por una conciencia crítica revocadora del sujeto y de la historia, la vuelta de la conciencia hacia ella misma o, más bien hacia su contrario, hacia lo rechazado por ella. La idea de una igualdad de los pueblos, que surge después de la guerra para imponerse con la descolonización, es una idea enteramente nueva que modifica todas las referencias para pensar el espacio geopolítico. La percepción de la humanidad se encuentra fuera de foco para el intelectual de Occidente; la identidad no se lee más desde el interior sino proyectada sobre un espacio exterior. Esta inflexión de la mirada impone que los espacios se vuelvan dialécticos y necesita los anteojos del antropólogo para escrutar el universo del otro.

Una ruptura radical se muestra en relación con la llustración y con la creencia de un progreso continuo, tal como lo expuso Condorcet. ${ }^{5} \mathrm{El}$ hombre occidental estaba en el centro del dispositivo de conocimiento y de juicio antes de sufrir el descentramiento de su punto de vista antropocéntrico. Esta revolución fue preparada desde finales del siglo XIX por una nueva estructura de pensamiento científico, de perspectiva estética, de escritura que privilegia la discontinuidad, la deconstrucción. De lo arbitrario del signo saussuriano a los nuevos modelos matemáticos y físicos, de la teoría cuántica a la dislocación de la perspectiva clásica con los impresionistas, luego con los cubistas, una nueva visión del mundo impone la discontinuidad, el distanciamiento del referente. Por tanto la razón occidental, desde finales del siglo XIX, fue trabajada desde el interior de ella misma por su pluralización; no se piensa ya como reflejo sino como figuras sucesivas y discontinuas de estructuras diferentes. El psicoanálisis acentúa este fenómeno mostrando que no hay continuidad posible entre consciente e inconsciente, sino una ruptura que necesita la presencia de un tercero en la cura psicoanalítica. Se asiste entonces a un despliegue infinito de epistemes que substituye al esquema unitario del evolucionismo. El desencuentro que se opera entre los siglos XIX y XX acentúa más esta mutación; al historicista siglo XIX europeo, que piensa la historia humana como una emancipación de las leyes de la naturaleza, se

\footnotetext{
${ }^{5}$ Condorcer, L'esquisse.
} 


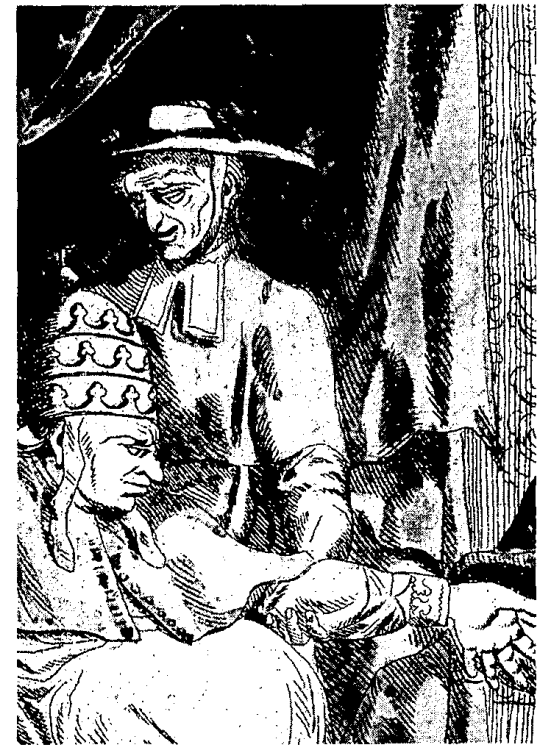

opone un siglo $\mathrm{xx}$ que toma su distancia de la historia para reconciliarse con una naturaleza percibida como ideal regulador, un paraíso por recobrar. Los combates que el hombre ha sostenido por los grandes valores de libertad y de igualdad ahora son considerados como dudosos, parciales y a menudo condenados al fracaso. Una conciencia planetaria, topográfica, rechaza la conciencia histórica. La temporalidad se vuelca en la espacialidad. El alejamiento del orden natural da lugar a una búsqueda de lógicas invariantes nacidas de la bisagra naturaleza/cultura. De cara a un futuro cerrado, la mirada se vuelve en busca de la naturaleza humana inmutable percibida en sus constantes: marcos mentales, ecosistemas, larga duración, estructura, extensión del concepto de lo geográfico, el paradigma de la naturaleza toma la revancha: "Hoy se ve cómo la desacralización de la historia, conlleva, por vasos comunicantes, una resacralización de la naturaleza." ${ }^{\text {S }}$ las rupturas son trágicas, se vuelve uno, para prevenirse, hacia las constantes y las fuerzas de atracción tanto culturales, étnicas, como naturales, en una marcha que apunta además a precaverse de la historia por la solidez del pedestal de la identidad, más que a construirla a partir de una lógica diacrónica significante. Los tartamudeos de la historia, el culto al pasado, las restauraciones que ocultan las rupturas de la superficie transforman al hombresujeto de su historia en objeto de una historia que lo rebasa. La relación del hombre con el hombre se encuentra "sometida a un estatuto zoológico". ' Las transformaciones de la sociedad occidental salidas de los Treinta Gloriosos han contribuido también a la dislocación de la relación pasado/presente/porvenir. Allí donde el devenir es reducido por la programación informática a una reproducción de modelos actuales proyectadosen el futuro, ningún porvenir diferente puede problematizarse. El fin de los terruños y el advenimiento de una sociedad fuera del suelo han contribuido a crear un estado de pesadumbre temporal, una relación fría con la temporalidad: "Lo que hace medio siglo se llamaba la aceleración de la historia [...] se ha convertido en el aplastamiento de la historia." De la misma manera esta relación atemporal se fragmenta en un miriada de objetos sin correlación, segmentación de saberes parciales, desarticulación del campo de los conocimientos y vaciamiento de los contenidos reales. Este bumus socioeconómico va a ser particularmente favorable para el éxito y la expansión de una lógica estructural, de una

\footnotetext{
${ }^{6}$ Debray, Critique, 1981, p. 299.

${ }^{7}$ Ibid., p. 52.

${ }^{8}$ Chesneaux, Modemitê, 1973 , p. 50.
} 
lectura de los síntomas, de un logicismo o de un formalismo que va a encontrar su coherencia fuera del mundo de los realia.

La poshistoria nos hace entrar en una relación nueva con un presente dilatado que se da como ahistórico, eterno reciclaje de las diversas configuraciones del pasado. Este presente, horizonte cerrado sobre sí mismo, no puede más que autorreproducirse en un presentismo dominante. La moda de las conmemoraciones ilustra bien esta nueva relación con la historicidad. La memoria rechaza la historia; ya no interesa la búsqueda de los orígenes para desarrollar las potencialidades del devenir, sino la simple evocación del universo delos signos del pasado que sobrevive en el presente inmutable. Signos que se reflejan entre sí y no tienen otros referentes que no sean los lugares de memoria, otros tantos rastros dejados en el espacio de un pasado percibido más allá de las líneas de una fractura insuperable. Conocemos "el fin de aquello que vivimos como una evidencia: la adecuación de la historia y la memoria". ${ }^{9}$ Estos lugares de memoria no son visitados de nuevo con una perspectiva reconstructora, sino simplemente considerados como los restos de un pasado rechazado, desaparecido; guardan todavía un valor simbólico e inauguran una relación archivística del tiempo pasado. Una discontinuidad radical opone la memoria de un pasado para siempre indefinible, invisible como real, excepto en la materialidad de estos signos múltiples, a un presente estacionario que recicla, conmemora, rememora. La relación con la temporalidad se encuentra estratificada y la memoria se pluraliza, se atomiza, carente de los diques constitutivos de una memoria plena. La historia vuelve sobre el instante, favorecida por

\footnotetext{
${ }^{9}$ Nora, Lieux, t. 1, 1984, p. xviII.
}

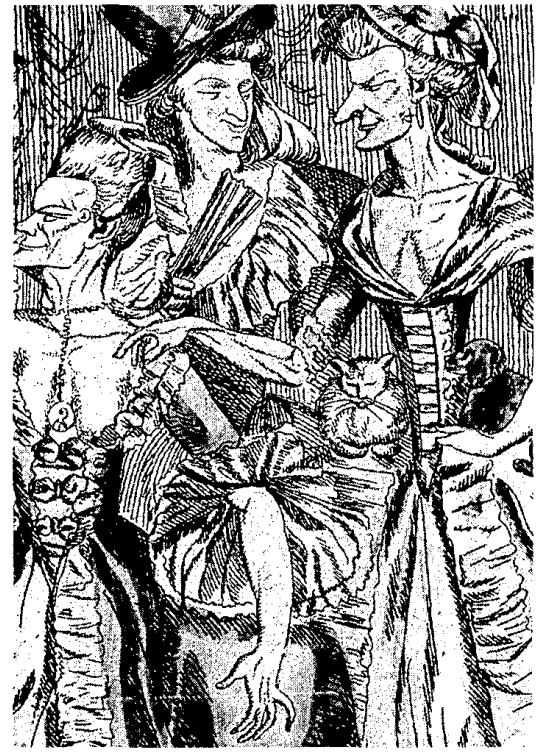

la unificación de los modos de vida y las mentalidades, una vez que no hay más acontecimientos verdaderos sino profusión de "noticias". El presente hunde sus ramificaciones en el pasado por medio de una relación puramente museográfica, sin apegarse a los lineamientos de la definición de un porvenir. La función misma del discurso histórico como interrelación entre pasado y porvenir se halla desestabilizada. El posmodernismo instaura una relación con la historia que puede ser asimilada a la del individuo senil que no puede más que coleccionar sus recuerdos, carente como está de toda posibilidad de proyecto porvenir. El éxito del estructuralismo corresponde entonces a un fenómeno global de civilización, va a tener como referente lo mismo la puesta en su lugar de una sociedad tecnocrática, que el hombre unidimensional que veía nacer Herbert Marcuse, que una reificación del hombre 
reducido a su dimensión de consumidor; desde este punto de vista, sin ser reducible a ella, se trata de la ideología de las no ideologías, la del fin de las ideologías revolucionarias, la de las ideologías coloniales... En los años sesenta, no obstante, este aspecto es lo no dicho, lo no consciente de transformaciones profundas que se revelaron como transparentes en los años ochenta y fueron reivindicadas en su positividad. Este proceso de pacificación, este fin de las rupturas significantes cierra el presente sobre sí mismo y hace que domine el sentimiento de repetición, de estancamiento; sociedad donde "lo nuevo se recibe igual que lo antiguo, donde la innovación se ha banalizado". ${ }^{10}$

Esta retirada de la historia, esta crisis de los discursos de legitimación propia de la posmodernidad, se han nutrido de un fondo pesimista, pero de un pesimismo activo por su crítica de las ilusiones de la razón y de una voluntad deconstructiva de todo lo que se daba como coherencia global, imperativo categóri$\mathrm{co}$, orden natural, sometido a la descomposición de una crítica radical. Se ha puesto en tela de juicio la noción misma de realidad; todo lo que lleva a sus categorías provoca sólo desilusiones, ella misma es relegada al orden de la insignificancia. En este punto el estructuralismo estaba en una etapa del proceso de deconstrucción por su facultad de desrealizar. Insensiblemente el espacio público se ha transformado en espacio publicitario en la era del simulacro, en el momento en que todos los polos de referencia se desvanecen, lo mismo que los marcos espacio-temporales con valores que se creían eternos y con vocación universal. La filosofia de la investigación del lado oscuro se hace eco en una estética de la

${ }^{10}$ Lipovetsky, L'ere, 1983, p. 11.

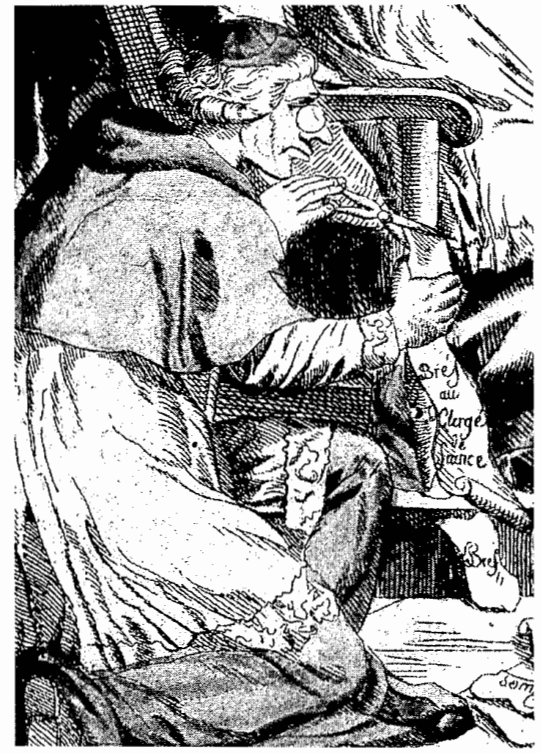

desaparición, tal como lo ve Paul Virilio, en la obra, donde el efecto de lo real suplanta a la realidad. Un escepticismo generalizado pone en crisis todo el metarrelato en la sociedad posindustrial o posmoderna. Según Jean-François Lyotard, ${ }^{11}$ esta transición hacia una nueva economía del discurso se sitúa a finales de los años cincuenta en Europa, o sea en el momento en que llega a su fin la reconstrucción. Con las tecnologías modernas de comunicación, con la computarización de la sociedad, se opera un cambio en el saber; éste se convierte en la cara indisoluble del poder de los que deciden, de los programadores que relegan poco a poco a la antigua clase política tradicional a representar un papel subalterno. La deconstrucción del uno, de los metadiscursos, da lugar a una proliferación de discursos múltiples no

${ }^{11}$ Lyotard, La condition, 1979, p. 11. 


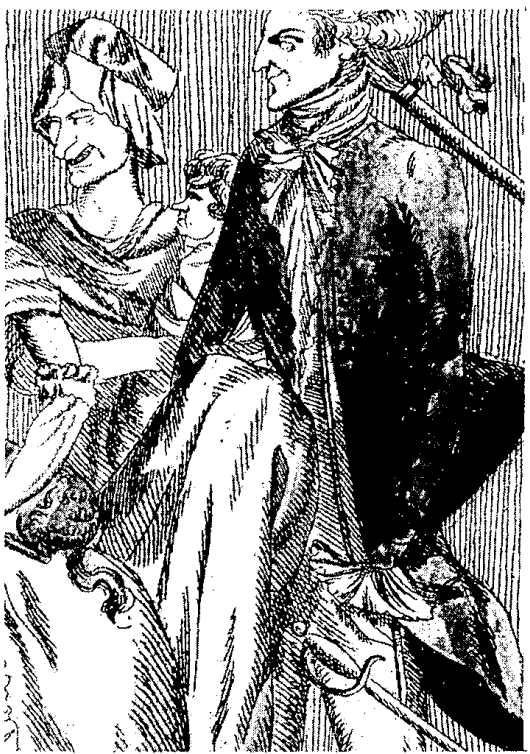

asignados a un sujeto, simples juegos del lenguaje, mera fibra sin tejido. El horizonte humanista se borra, es reemplazado por una postura representativa. El estructuralismo respondia a la crisis de los discursos de legitimación reduciendo las ambiciones del hombre a dimensiones provincianas, simple parte adherente, sin privilegios, de los seres vivos del planeta que soporta una historia que no le pertenece más, a escala geológica.

\section{UNA TEMPORALIDAD FRÍA}

En este aspecto, Lévi-Strauss es la representación más eminente de este pesimismo básico, de esta retirada del hombre. Tiene una de las visiones más críticas sobre la evolución de la modernidad occidental, a la que opone un escepticismo y un pesimismo profundos que lo hacen seguir el rumbo de una larga tradi- ción del pensamiento conservador que va de Burke a Ariès. "Aceptaría con gusto el reproche de pesimismo, si se me concede agregar el calificativo de sereno." ${ }^{\prime 2}$ La mirada desengañada se acentúa más por la posición misma del antropologo que ve desaparecer bajo los pies su campo de estudio a causa de los ataques bruscos y violentos de una aculturación a menudo forzada. Esta desaparición del terreno específico del etnólogo lo obliga a replegarse sobre su sociedad de origen, sobre la que puede en efecto aplicar sus métodos de análisis, pero a partir de la uniformación de la modernidad que impone sus leyes. Lo que escruta Levi-Strauss es por lo tanto una atmósfera crepuscular; después del crepúsculo de los dioses, el de los hombres: "El día se aproxima en que la última de las culturas que nosotros llamamos primitivas habrá desaparecido de la superficie de la tierra. ${ }^{13} \mathrm{Al}$ término de su tetralogía sobre los mitos, LéviStrauss concluye, desengañado, con una involución de los recursos de la combinación universo/naturaleza/hombre que terminan por "aniquilarse ante la evidencia de su caducidad" ${ }^{14}$ Desde 1955 LéviStrauss lanzó a Occidente la advertencia de los desastres. Con Tristes trópicos se proponía hacer revivir las sociedades primitivas sumergidas bajo "nuestra basura" lanzada a la cara de la humanidad, el hormigón que brota por todas partes como la grama, el empobrecimiento de las chabolas, la deforestación de los bosques. Triste balance de una civilización conquistadora y dadora de lecciones, como la de la muerte asestada detrás del rostro hipócrita de la aventura y del encuentro del otro. La antropología estructural de Lévi-Strauss la emprende contra

12 Lévi-Strauss, "Entrevista con Jean Marie Benoist", Le monde, 21 de enero de 1979.

${ }^{13}$ Lévi-Strauss, Antbropologie, 1973, p. 65.

${ }^{14}$ Lévi-Strauss, L'bomme, 1971, p. 620. 
la Ilustración, contra la pretensión de un mensaje con vocación universalizante. Por cierto, las sociedades que estudia tienen una relación diferente con la temporalidad si se comparan con las sociedades occidentales; se preservan del cambio y se perciben como diques de resistencia contra las perturbaciones potenciales endógenas y exógenas. De allí la famosa distinción que hace Lévi-Strauss entre sociedades frías y sociedades calientes; habrá pues un desacoplamiento que dejará al etnógrafo toda una parte de la humanidad próxima al grado cero de temperatura histórica y que reservará al historiador las sociedades calientes. Con esta distinción, Lévi-Strauss aplica el modelo de obra en general -es decir, el de la termodinámica- al paradigma estructuralista, el cual opone a las sociedades unanimistas que no tienen necesidad de funcionar con desviaciones diferenciales y a las que califica de sociedades mecánicas, "relojes, en comparación con las máquinas de vapor". ${ }^{15}$ Para las sociedades primitivas la categoría de historia no tiene sentido puesto que lo que no figura en la estructura inicial de su funcionamiento está desprovisto de sentido; pero Lévi-Strauss no se contenta con oponer dos modos de relación a la historicidad, su ambición no es descodificar el modelo de una provincia de la humanidad, por el contrario, concibe el modelo estructuralista como clave de lectura con vocación universal. A este respecto retoma fielmente las enseñanzas de Ferdinand de Saussure, quien a principios de siglo en su Curso de lingüistica general otorgaba una prevalencia absoluta a la sincronía para negar toda validez a la diacronía, a la historicidad. La historia es por tanto negada, cualquiera que sea la latitud; si hay alguna

\footnotetext{
${ }^{15}$ Lévi-Strauss, "Entrevista", 1969.
}

ruptura significante que parezca conceder Lévi-Strauss es la revolución del neolítico. La historia no es más que un agente de erosión, de degeneración, de pérdida de energía: "El hombre no crea verdaderamente en grande sino en el comienzo. ${ }^{16}$ A este respecto Lévi-Strauss se sitúa en la doble filiación de la lingüística estructural y de su maestro Jean-Jacques Rousseau, para quien era necesario recobrar la pureza original. Así, resulta ser "el vicario de los trópicos", que desarrolla'todoun discurso nostálgico acerca de los orígenes perdidos. El designio de la antropología estructural es descubrir las formas invariantes más allá de los diferentes contenidos; desde las estructuras elementales del parentesco hasta los mitos, siempre se trata de estructuras que funcionan como verdaderas "máquinas de suprimir el tiempo"." Para deshacerse de la aproximación histórica, Lévi-Strauss, que no puede negar la existencia de los acontecimientos, en los que reconoce al mismo tiempo "la pertinencia de la inanidad", ${ }^{18}$ postula una relación de exterioridad entre estructuras y acontecimientos, lo que permite el despliegue estructural y por lo tanto un análisis liberado del substrato que describe los acontecimientos. Es al término de su largo recorrido por las mitologías cuando Lévi-Strauss hace manifiesta su ambición de liberarse del tiempo, de la historia. "Llevado hasta sus últimas consecuencias, el análisis de los mitos alcanza un nivel en que la historia se anula por sí misma. ${ }^{n 19}$ Este tiempo de los mitos restituido por Lévi-Strauss no sólo es recobrado sino "suprimido". La aproximación estructuralista que se daba como

\footnotetext{
${ }^{16}$ Lévi-Strauss, Tristes, 1955, p. 442.

${ }^{17}$ Lévi-Strauss, Le crue, 1964, p. 22.

18 Lévi-Strauss, Du miel, 1967, p. 408.

${ }^{19}$ Lévi-Strauss, L'bomme, 1971, p. 542.
} 
modelo metodológico transforma entonces lo real en estático, en entidad reversible, y así encuentra por realizar una isología entre el transcurrir y su objeto, percibido como sistema cerrado con autorregulación. La historia, desde el punto de vista de esta isología, no es más que un mito que Lévi-Strauss denuncia, especialmente en su polémica con Sartre, cuando en 1962 da una respuesta a la Crítica de la razón dialéctica en El pensamiento salvaje.

La historia nunca es la historia sino la historia-para. Parcial, aunque ella misma se prohíba serlo to que incluso es un modo de parcialidad-, permanece inevitablemente parcial.$^{20} \mathrm{La}$ historia conduce a todo, pero a condición de salir de ello. ${ }^{21}$

\section{El tiempo se percibe como un peligro,}

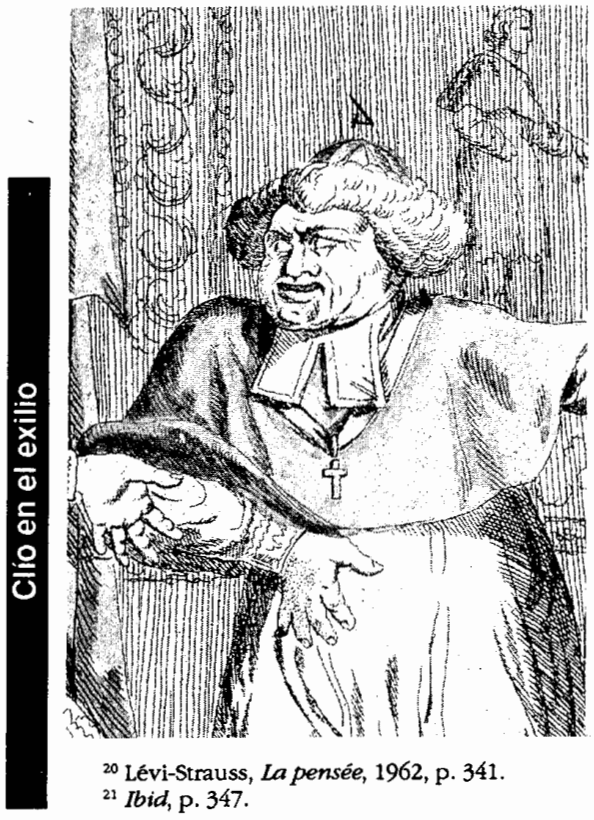

un mito cuyo riesgo hay que exorcizar para alcanzar las invariancias escondidas bajo la multiplicidad y el desorden sublunar. Un naturalismo estructural anima la marcha de su ambición científica en la medida en que Lévi-Strauss no concibe solamente la estructura como modelo heurístico para construir su objeto de estudio, sino como "ya ahí", en la realidad subyacente y, más precisamente, la localiza en los marcos mentales. Al término de su investigación sobre los mitos, la lección sacada de su estudio se halla en el hecho de que ellos permiten "aislar ciertos modos de operación del espíritu humano, muy constantes a lo largo de los siglos" 22 En esta búsqueda de marcos mentales se encuentra al mismo tiempo el retorno a la vieja noción de la naturaleza humana intemporal, ahistórica y la disolución de una aproximación específica a las ciencias sociales, y un descentramiento del hombre en provecho de un biologismo reductor basado en los genotipos universales, eludiendo la dimensión social de las sociedades. Esta ambición cientificista de la antropología estructural asigna no obstante un lugar a la historia, pero en un tono menor. La historia compete a lo empírico, a lo concreto, a lo singular y desde este punto de vista no tiene lugar en el plano científico sino como dato en bruto que debe trabajarse, desmitificarse. Se trata de un material inabarcable como material etnográfico, pero en el ámbito de la antropología se llega a las leyes, a las reglas, al concepto, a un nivel más alto de abstracción. La historia no es más que la contingencia y el "milagro griego", el tránsito del pensamiento mítico a la filosofia es un simple hecho del azar. La otra dimensión que separa la antropología estructural de la historia se sitúa en la

\footnotetext{
${ }^{22}$ Lévi-Strauss, L'bomme, 1971, p. 571.
} 
profundidad del transcurrir. Si eletnólogo puede llegar al inconsciente de una sociedad, el historiador, en cambio, está condenado a permanecer en el plano consciente.

El etnólogo camina hacia adelante, tratando de alcanzar siempre más inconsciente hacia donde quiera que se dirija; mientras que el historiador avanza, por así decirlo, retrocediendo, manteniendo los ojos fijos sobre las actividades concretas y particulares. ${ }^{23}$

Ahora bien, si la historia está sujeta a lo consciente, este nivel es para Lévi-Strauss el más pobre de las ciencias del hombre: "la conciencia es la enemiga secreta de las ciencias del hombre". ${ }^{24}$ Este enfriamiento de la temporalidad, común a la lingüística y a la antropología estructurales, indujo a una relación descontinuadora entre las diversas épocas de la historia: "La lengua no pudo nacer sino de un solo golpe." ${ }^{25}$ Este descontinuismo no preocupa mucho a Lévi-Strauss, quien se apega más bien a la circularidad del tiempo, a las zonas inmóviles, pero va a ser teorizado por la generación siguiente, que tendrá en cuenta la historicidad aunque de una manera nueva. El desafio estructuralista a la historia tendrá también una gran influencia sobre el discurso de los propios historiadores, que modificarán su relación con la temporalidad en la investigación de las invariancias, de la larga duración de las estructuras. ${ }^{26}$

\section{EL DECONSTRUCTIVISMO}

La generación siguiente, apoyándose en

\footnotetext{
${ }^{23}$ Lévi-Strauss, Antbropologie, 1958, p. 32.

${ }^{24}$ Lévi-Strauss, Reune, 1964 , p. 583.

${ }^{25}$ Lévi-Strauss, "Introduction", 1968, p. 10.

${ }^{26}$ Dosse, L'bistoire, 1987.
}

la reflexión epistemológica encabezada por Cavaillès, Bachelard y Canguilhem, va a tener en cuenta la historicidad para mejor denunciar el historicismo. La historia no está colocada en situación de exterioridad en relación con la estructu$\mathrm{ra}$, sino deconstruida desde el interior. La deconstrucción va a tomar dos formas: una nietzscheana con Michel Foucault, otra heideggeriana con Jacques Derrida. Se trata de lo que los americanos llamarán posestructuralismo, concepto no fundado en lo cronológico ya que esta etapa es contemporánea del apogeo del paradigma estructuralista y participa plenamente de él, a pesar de los desplazamientos que implica. La figura del hombre que se borra, con to a la orilla del marun rostro dibujado en la arena al final de Laspalabras y las cosas, es totalmente nietzscheana. Para Michel Foucault la primera ruptura con la antropología data de Nietzsche, quien es responsable de esta definición del hombre. La muerte de Dios anuncia la desaparición del hombre, su inminencia está en la promesa-amenaza del advenimiento del superhombre. Toda la obra de Foucault parece responder al programa trazado por Nietzsche en La gaya ciencia. "¿Dónde pues se ha emprendido alguna vez una historia del amor, de la codicia, de la envidia, de la conciencia, de la piedad, de la crueldad? ${ }^{27}$ Respondiendo a la incitación de Nietzsche, Foucault va a escribir una historia del contrario de la razón occiiental y a substituir la temporalidad con sus ritmos diferenciados, el estudio de la espacialidad discursiva, de los diversos pliegues $\mathrm{d} / \mathrm{d}$ discurso en el nivel superficial, en el mundo de lo visible, de la transparencia. Una mirada en el espacio que sabe desde donde mira y lo que mira. El nominalismo de Foucault, quien va a

${ }^{27}$ Nietzsche, Le gai, 1964, cap. vil. 
privilegiar las formaciones discursivas, las palabras en relación con las cosas, los enunciados en relación con las formaciones sociales, encuentra sus raíces en Nietzsche, para quien la filosofia es una suerte de filología en suspenso, donde no hay que interpretar el significado original puesto que todo discurso es ya una interpretación.

Tal aproximación a la historia de la humanidad se desea esencialmente relativista; ya no hay ni continuidad de la cual asirse ni racionalidad en juego en el pensamiento y la acción del hombre; puesto que el sujeto se encuentra cogido por las redes del objeto en un vínculo indisoluble y cambiante, ninguna mirada es estable. La genealogía nietzscheana intenta descubrir detrás de los valores -vueltos absolutos- de deber, de moral, de falta, el fondo de este universo, y al señalar su proveniencia descubre el caos de lo accidental, del azar, de la dispersión de fuerzas y debilidades que hacen pedazos lo que Occidente tomaba como fundador de nuestra humanidad. Nietzsche trata de descubrir las diferencias entre la práctica y el sentido; de ahí Foucault saca uno de sus paradigmas más quirúrgicos, el de la discontinuidad, el de una fisura más espacial que temporal entre dos modos de pensamiento, entre dos epistemes. Falla en el interior de nosotros mismos que Foucault, siguiendo a Nietzsche, intenta redescubrir más allá de las falsas constancias, de las permanencias ilusorias:

Es necesario hacer pedazos aquello que permita el juego consolador de los reconocimientos. [...] La historia serä efectiva en la medida en que introduzca lo discontinuo en nuestro ser mismo. [...] El sabér no está hecho para comprender, está hecho para dilucidar. ${ }^{28}$

${ }^{28}$ Foucault, "Nietzsche", 1971, p. 160.

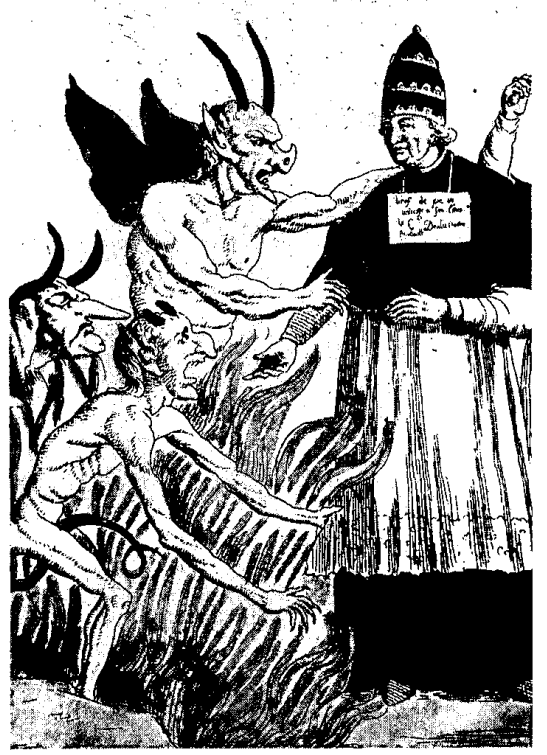

1 4

La genealogía nietzscheana vuelve a poner en tela de juicio a la economía de la causalidad, a la investiga ción clásica de los origenes temporales, $\mathrm{y}$, al contrario, descifra los diversos códigos en vigor a partir de lo que excluye, a partir de las ausencias. Se topa uno con la conmoción de la historia por el sesgo que toma la obra de Foucault y por su tentativa de deconstrucción del sujeto de la razón occidental, para mejor atrapar a su opuesto. La genealogía se asimila aquí a un positivismo crítico en la medida en que limita su campo a la disociación de lo verdadero y lo falso sin tratar de poner en su lugar algún sistema de causalidad. Se apegará a los azares más que a las leyes, a las discontinuidades más que a las contradicciones que operan en las continuidades, a lo descriptivo de las positividades materiales más que a su coherencia interna y fundamentos temporales. La genealogía debe entonces romper con la continuidadhistórica para señalar la 
singularidad de los acontecimientos más allá de toda finalidad, acosar a la historia alli donde ha sido rechazada por el reino de lo ilusorio, aquel de la razón especialmente, en todo aquello que ha sido lanzado por la borda mientras el hombre afirmaba su reino gracias a su facultad de racionalizar: los sentimientos, los instintos, el amor... Foucault se inscribe en un pensamiento positivista, sin duda crítico, pero que vuelve a convertir la historia en descripción de acontecimientos: "La historia efectiva hace resurgir el acontecimiento en aquello que puede haber perdido de único y de agudo. [...] Vivimos una miriada de acontecimientos perdidos." ${ }^{29} \mathrm{El}$ acontecimiento singular, lo discordante, el hombre, se hallan atrapados en un laberinto, mundo informe sin arquitectura, donde él se disuelve, donde toda forma de conciencia se ha vuelto ilusoria. El lugarde la genealogía nietzscheana y foucaultiana se halla esencialmente en el nivel de articulación del cuerpo y de la historia. "El cuerpo: superficie de inscripción de los acontecimientos, lugar de disociación del yo. ${ }^{30}$ Se reencuentra al cuerpo como objeto privilegiado de la reflexión de Foucault en la mayor parte de sus trabajos, lo mismo en relación con el saber médico, con la razón punitiva, que a propósito de la historia de la sexualidad. El cuerpo contra la razón, el deseo contra la ley y la norma, lo múltiple de las pulsiones contra el uno del universo codificado. En esta articulación, el absoluto, la totalidad histórica, son desestructurados en provecho de la dispersión, del juego de las diferencias, de una disociación de la unidad del ser humano, de una historización de los sentimientos. En esta genealogía todo es historia, pero la historia ya no es un todo, nada debe escapar a la mirada, pero no se

${ }^{29}$ Ibid., pp. 161-162.

${ }^{30}$ Ibid., p. 154. produce ningún sentido. "Es uno de los rasgos de la historia estar sin elección: ella se impone la tarea de conocerlo todo sin jerarquía de importancia." ${ }^{31}$ Nietzsche ataca la objetividad historiadora que participa de un discurso teleológico. Este historiador de ningún tiempo y de ningún lugar, a la Fenelon, no es más que un mito que debe destruirse para restablecer a quien habla desde su singularidad:

Yono puedo soportar a esos concupiscentes eunucos de la historia, a todos esos chambones del ideal ascético; no puedo soportar esos sepulcros blanqueados que producen la vida; no puedo soportar a estos seres fatigados y debilitados que se envuelven en la sabiduria y se echan una mirada objetiva. ${ }^{32}$

El sentido histórico, tal como lo entienden Nietzsche y Foucault, se opone término a término a las tres modalidades platónicas de la historia, y en este sentido nos remite a menudo al sofisma, con el uso paródico y destructor de la identidad y el uso sacrificial y destructor de verdad que se oponen a la historia-reconocimiento, a la historia-continuidad y a la historia-conocimiento. "Se trata de hacer de la historia una contramemoria y de ella desplegar como consecuencia toda una forma diferente del tiempo. ${ }^{n 3}$ Entonces su perspectiva es la de una escritura de antimemorias, de una obra deconstructiva donde el hombre debe desaparecer en un halo en el que se desvanece su figura. En este nivel, la correspondencia entre Nietzsche y Foucault es total: "Perecer por el conocimiento absoluto bien podría formar parte del fundamento del ser. ${ }^{.34}$ La genealogía tiene por objeto irrealizamos más que ir en

\footnotetext{
${ }^{31}$ Ibid., p. 164.

${ }^{32}$ Nietzsche, Généalogie, 1963, 111.

${ }^{33}$ Foucault, "Nietzsche", 1971, p. 167.

${ }^{34}$ Nietzsche, Par-delà, p. 39.
} 
busca de alguna identidad; en cuanto a la historia, se ha convertido en este retorcimiento del tiempo, en un gran carnaval: "La genealogía es la historia como carnaval concertado." ${ }^{35}$ Del rechazo violento en Las consideraciones intempestivas, de una historia negada en nombre del presente, Nietzsche pasa, con La genealogía de la moral, a volver a tomar en cuenta las tres modalidades de la historia denunciadas en 1874, pero metamorfoseadas en su contrario. Parodia, disociación, destrucción del sujeto, surgimiento del cuerpo, discontinuidad, tantos atajos que Michel Foucault toma prestados de él y que constituyen lo esencial de su filosofia, sus paradigmas fundadores.

En esta filiación nietzscheana, Michel Foucault la emprende contra el historicismo, contra la historia como totalidad, como continuo histórico; es necesario renunciar a todas las "continuidades irreflexivas mediante las cuales se organiza de antemano el discurso que intenta analizar" ${ }^{36}$ La historia debe renunciar a la construcción de las grandes síntesis e interesarse, por el contrario, en la fragmentación de los saberes. Foucault procede a hacer una deconstrucción de la historia, un desmembramiento de ésta en una constelación vuelta informe a partir de la cual toda unidad temporal es facticia. Por consiguiente Foucault va a apoderarse del territorio del historiador, no para investigar en él las coherencias diacrónicas sino para establecer coherencias sincrónicas. Así, descubre la sucesión de las tres epistemes en Las palabras y las cosas. Entre estos estados sincrónicos del saber, ninguna filiación, un simple resurgimiento, verdadero desgarramiento creador que hace caer de una a otra episteme. Esta marcha

\footnotetext{
35 Foucault, "Nietzsche", 1971, p. 168.
}

${ }^{36}$ Foucault, L'archéologie, 1969, p. 36.

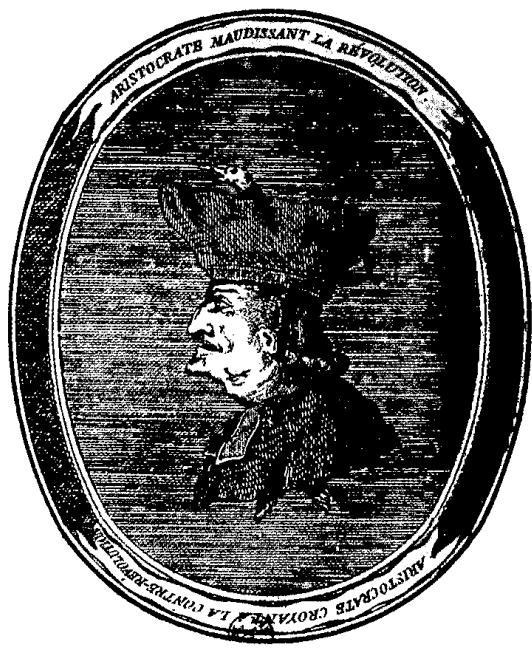

1

4

9

estructuralista es de hecho ahistórica en sus postulados, y es reivindicada como tal por Foucault:

Una tarea como ésta implica que sea puesto en duda todoloque pertenece al tiempo, todo lo que esta formado en él [...] de manera que aparezca el desgarrón sin cronología y sin historia del que proviene el tiempo. ${ }^{37}$

La discontinuidad aparece entonces en su singularidad, no reductible a un sistema de causalidad en la medida en que ella ha sido cortada de raíz, figura etérea salida del caos. Esta deconstrucción conduce a su teorización en La arqueología del saber con la noción de historia seriada predicada por Foucault: "En adelante el problema es constituir las series. ${ }^{38}$ Cada una de las series tiene su

${ }^{37}$ Foucault, Mots, 1966, p. 343.

38 Foucault, L'archeologie, 1969, p. 15. 
propio ritmo, sus rupturas significantes, fuera del contexto general; ya no hay motor en una evolución, sino discontinuidades en las revoluciones. El historiador se vuelve entonces arqueólogo del saber, confinado a su descripto, que renuncia a la totalidad, y Foucault llegará a oponer a la noción de historia totál la de historia general que, "al contrario, extenderá el espacio de una dispersión". ${ }^{39}$ Detrás de esta búsqueda de discontinuidades se halla el paradigma estructuralista del afloramiento de los estratos inmóviles, de invariantes: "Detrás de la historia atropellada de los gobiernos, las guerras y las hambrunas, se destacan las historias casi inmóviles bajo la mirada, las historias con inclinación débil. " ${ }^{40}$ En esta ambición de restituir las zonas estáticas a partir de discontinuidades, no hay gran ruptura con el programa de LéviStrauss, tal como lo enunció en 1950 en la "Introducción a la obra de M. Mauss".

La otra vertiente del deconstructivismo histórico se nutre del pensamiento heideggeriano, y la obra de Jacques Derrida es la que mejor representa esta tentativa. La filosofia derridiana la emprende contra toda forma de logocentrismo que él ataca lo mismo en el discurso tradicional de la metafísica que en lo que se da como discurso de la modernidad: Saussure, Lévi-Strauss, Foucault... Es el más radical en lo que podría llamarse "una estrategia general de la deconstrucción". "A la búsqueda de la verdad, de la génesis, del sentido, Jacques Derrida opone una escritura descontextualizada, totalmente independiente del contexto, lo mismo del locutor (el que habla) que de su destinatario. Esta tendencia a la autonomía, que no hace sino retomar el para-

\footnotetext{
39 Ibid., p. 19.

40 Ibid., p. 10.

${ }^{41}$ Derrida, Positions, 1972, p. 56.
}

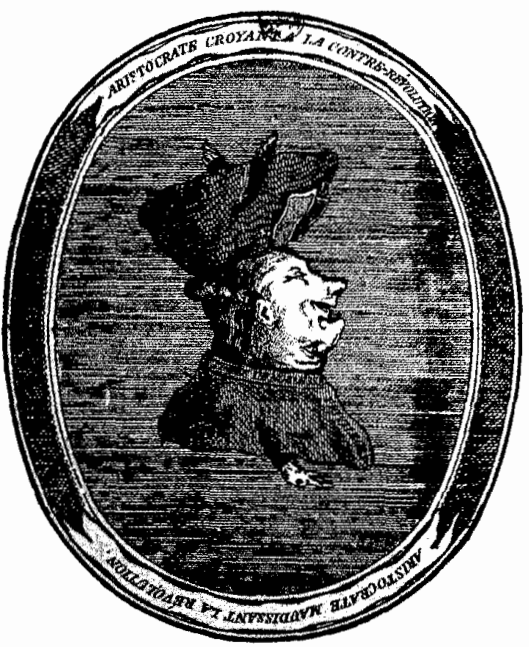

digma estructuralista de descartar el referente y el sujeto que habla, Derrida la lleva hasta el extremo de reducir toda forma de aparición del decir, como substrayéndose a la presencia por su desaparición inmediata, y de enunciar un cierto número de conceptos, de figuras retóricas, para dar cuenta de este fenómeno de las unidades del simulacro de lo real, de los "indecidibles", como los términos pharmakon, suplemento, himeneo, gramo, espaciamiento. Todas estas figuras ilustran un proceso global de diseminación:

Germinación, diseminación. No hay inseminación primera, la simiente está dispersa desde el principio. [...] Cada germen es su propio término, tiene su término no fuera de sí sino en sí como su límite interior, haciendo ángulo con su propia muerte. ${ }^{42}$

${ }^{42}$ Derrida, Dissémination, 1972, pp. 337-338. 
Aquí se encuentra la temática heideggeriana del ser, jamás escindido del ente, substrayéndose también a su presencia al mostrarse en el ente, asi como toda una filosofia vuelta hacia el ser-para-la-muerte, hacia el destino trágico de este arrancamiento del ser, cada vez más profundo y soterrado, sepultado en las ilusiones del ente: "Todo grafema es testamentario por esencia." ${ }^{43}$ ¿Qué hay en esta deconstrucción de la noción de historicidad? Es evidente que implica una nueva relación con la temporalidad, fuera de la lógica de la identidad, se organiza alrededor de la noción de diferencia, ya sea la noción estructuralista de diferencia, del otro, a la cual sehaninclinado lostrabajos de Lévi-Strauss, Foucault o Lacan, pero también en el sentido de diferir en el tiempo, medio de evitación de la presencia. Como Foucault, Derrida recusa el ahistoricismo de LéviStrauss pero no por eso se adhiere al "carácter metafísico del concepto de historia"; ${ }^{44}$ como Foucault, le opone la concepción de una historia "monumental, estratificada, contradictoria". ${ }^{45}$ Esta historia es una historia pluralizada, fundamentalmente heterogénea, se emparienta con la historia seriada definida por Foucault y con su recusación de la significación globalizante de la historia que no se puede construir más que sobre un fondo ontológico. La noción de historia es por lo tanto caduca: "¿A partir de qué núcleo semántico mínimo se nombrará todavía historia a estos tipos de historia heterogéneos, irreductibles, etc.?" ${ }^{\text {46 }}$ La deconstrucción va a trastornar la escritura historiadora de los historiadores profesionales. En los años sesenta, ya más sensibles a las zonas inmóviles de la temporalidad, en el momento en que Fernand Braudel domi-

\footnotetext{
43 Derrida, Grammatologie, 1967, p. 100.

4 Derrida, Positions, 1972, p. 77.

4 Ibid., p. 77.

4 Ibid., P. 80.
}

naba el imperio de las ciencias sociales, los historiadores van a renunciar al concepto de sintesis, de globalidad, en que hasta ese momento se fundaba su obra, y la tercera generación de los Annales va a escribir entonces una historia en migajas. ${ }^{47} \mathrm{De}$ ahí en adelante la totalidad ya no será pensada en correlación con las diversas instancias de lo real, sino como aquella del objeto mismo de investigación en su singularidad y en el lugar que le corresponde en la serie a que pertenece. En recompensa, esta pluralización axiomática es saludada por el filósofo Jean-Marie Benoist: "Toca al filósofo levantar acta de esta explosión de la historia." 48

Esta nueva problematización filosófica, ya sea de Lévi-Strauss, de Foucault o de Derrida y de todo el pensamiento estructuralista, más allá de su diversidad extrema, tiene sus raíces en esa retirada de la historia propia de la posmodernidad, en ese pesimismo que fue no sólo sereno sino fecundo. Carente de perspectiva histórica, habiendo desestabilizado el estatuto del hombre y tomado distancia de la realidad delo real, el estructuralismo ha hecho prevalecer los sistemas cerrados, lugares de refugio de métodos con vocación científica; lugar inaccesible, constreñido a la otra escena, a distancia de la conciencia. La creciente complejidad de lo social y la incapacidad para comprender la lógica unificante han favorecido este repliegue sobre la búsqueda de una unidad de la cara oculta de lo real, desplazamiento del positivismo al otro lado del espejo. El sentido revelado se hunde en la insignificancia porque ya no forma parte del campo cerrado de este universo de los signos que se remiten entre sí en ausencia de toda causalidad material, en situación de exterioridad, en

\footnotetext{
${ }^{47}$ Dosse, L'bistoire, 1987.

${ }^{48}$ Benoist, Rétolution, 1980 , p. 327.
} 
relación con el referente. La verdad del sistema cerrado ya no será investigada por una hermenéutica que parte de la significación revelada, sino que deberá tomar las relaciones e interrelaciones entre signos en el interior de la estructura delimitada y del juego que ella define entre los signos. De este entrelazamiento de las relaciones, tanto la contingencia histórica como el libre juego de la iniciativa son igualmente desterrados. Si el modelo de aproximación privilegiado es la lingüística estructural, se pueden hallar algunas similitudes en el comportamiento cibernético que descentra la perspectiva finalista y antropocéntrica para privilegiar los procesos de autorregulación. La combinación de una física de las relaciones, los juegos y rejuegos del yo y del otro descentran al hombre, que no ocupa más que un lugar ilusorio. "Necesitamos por fuerza romper esta maraña de apariencias que llamamos el hombre." 49

A la hora en que las ciencias humanas parecen fascinadas por el modelo cibernético, la variable humana -en sus componentes psicológico e histórico-se vuelve inconsistente y debe dejarellugar a un método riguroso que se desea con un nivel de eficacia similar al de las cien'cias exactas. El sistema cerrado que se impone va a hacer pagar un alto precio por su distanciamiento del mundo real; no obstante, habrá una eficacia notable por la apertura del campo del saber que va a augurar. El estructuralismo, en su búsqueda del inconsciente de las prácticas sociales, va a abrirse al universo de los signos de lo simbólico, de las representaciones colectivas, de los ritos y costumbres en su lógica interna, del estrato de lo que no está explícito en las huellas de la actividad humana. El acceso a estos

${ }^{49}$ Daix, Structuralisme, 1971, p. 28. nuevos objetos, su pluralización, va a contribuir a la fragmentación de los sistemas de causalidad. En verdad el método estructural ha permitido triunfar a los causalismos o a los determinismos simplistas, pero la coherencia unificadora de la historia social se ha desvanecido en las arenas movedizas de su combinación que reviste el doble aspecto de la unidad y de su pluralización, juego dialéctico del yo y de la alteridad, que abre la nueva era de una poshistoria.

\section{BiBLIOGRAFÍA}

-Benoist, Jean-Marie, La révolution structurale, Denoël, París, 1980.

-Chesneaux, Jean, De la modernité, Maspéro, París, 1973.

-Condorcet, Jean Antoine Nicolas, marqués de, L'esquisse d'un tableau bistorique des rapports de l'esprit bumain. (Bosquejo de un cuadro bistórico de los progresos del espiritu bumano, Espasa Calpe, Madrid, 1921.]

-Daix, Pierre, Structuralisme et révolution culturelle, Casterman, París, 1971.

-Debray, Régis, Critique de la raison politique, Gallimard, Paris, 1981.

- Derrida, Jacques, De la grammatologie, Minuit, París, 1967.

rís, 1972.

La dissémination, Le Seuil, Pa,Positions, Minuit, París, 1972.

-Dosee, François, L'bistoire en miettes, des Annales á la nouvelle bistoire, Découverte, París, 1987.

-Foucault, Michel, L'arcbéologie dusavoir, Paris, 1969.

"Entrevista con Knut Boessers, "Die folter das ist die vernunft", Literaturmagazin, núm. 8, Reibek: Rowohlt, 1977. mard, Paris, 1966.

Les mots et les choses, Galli"Nietzsche, le généalogie, l'histoire", en Suzanne Bachelard, Hommage á Jean Hyppolite, PUF, París, 1971.

-Lévi-Strauss, Claude, Anthropologie structurale, Plon, París, 1958. 


\section{SECUENCIG}

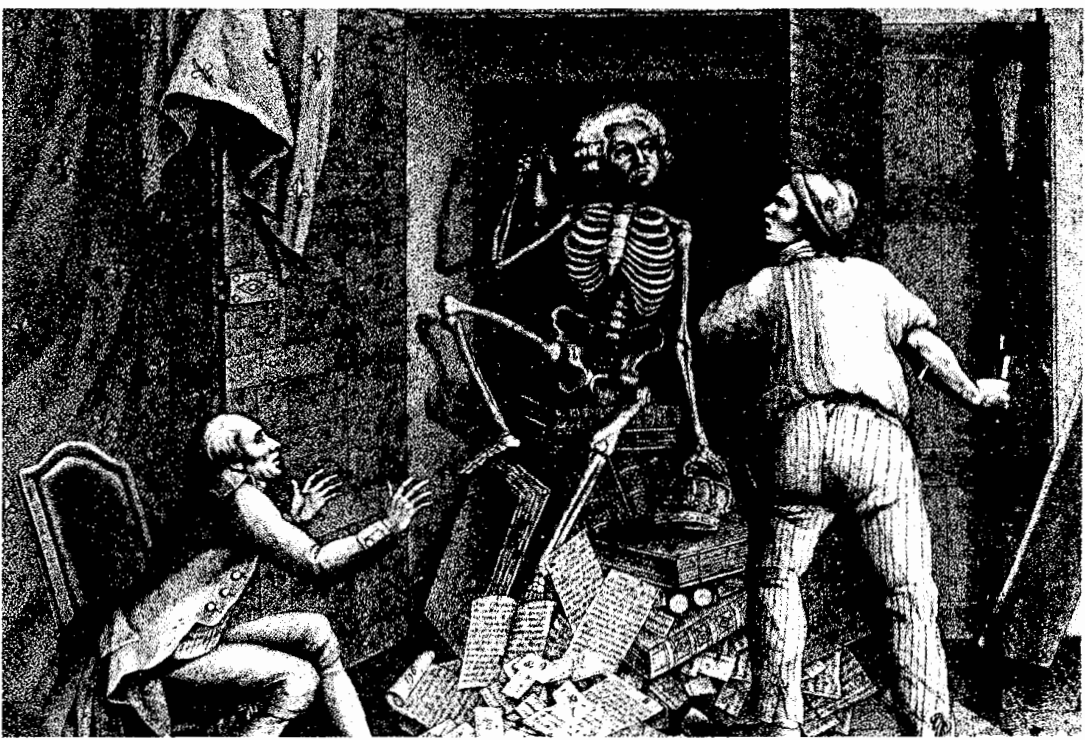

Plon, París, 1973.

Anthropologie structurale II, 1964

Le crue et le cuit, Plon, París, París, 1967.

Du miel aux cendres, Plon,

-, Entrevista con Georges Charbonnier, Plon, Paris, 1969. [En español se conoció como Arte, lenguaje, etnografía, Siglo XXI Editores, México, 1975.]

L'bomme nu, Plon, París, 1971.

"Introduction á l'oeuvre de M.

Mauss", Sociologie et antbropologie de $M$. Mauss, PUF, París, 1968.

1962.

La pensée sauvage, Plon, París, sciences sociales, 1964.
1955.

Tristes tropiques, Plon, Paris,

-Lipovetsky, Gilles, L'ère du vide, Gallimard, Paris, 1983.

-Lyotard, Jean-François, La condition postmoderne, Minuit, París, 1979.

225 , diciembre de 1985.

Le Magazine Littéraire, núm.

-Nietzsche, Friedrich, Le gai savoir, Gallimard, París, 1964.

La généalogie de la morale, III,

Gallimard, París, 1963.

Par-delá le bien et le mal. [Más

allá del bien y del mal, Alianza, Madrid, 1975.]

-Nora, Pierre, Les lieux de mémoire. La

République, Gallimard, Paris, 1984, t. I.

-Torres, Félix, Déjà vu, Ramsay, París, 1986. 


\section{SECUENCIA}

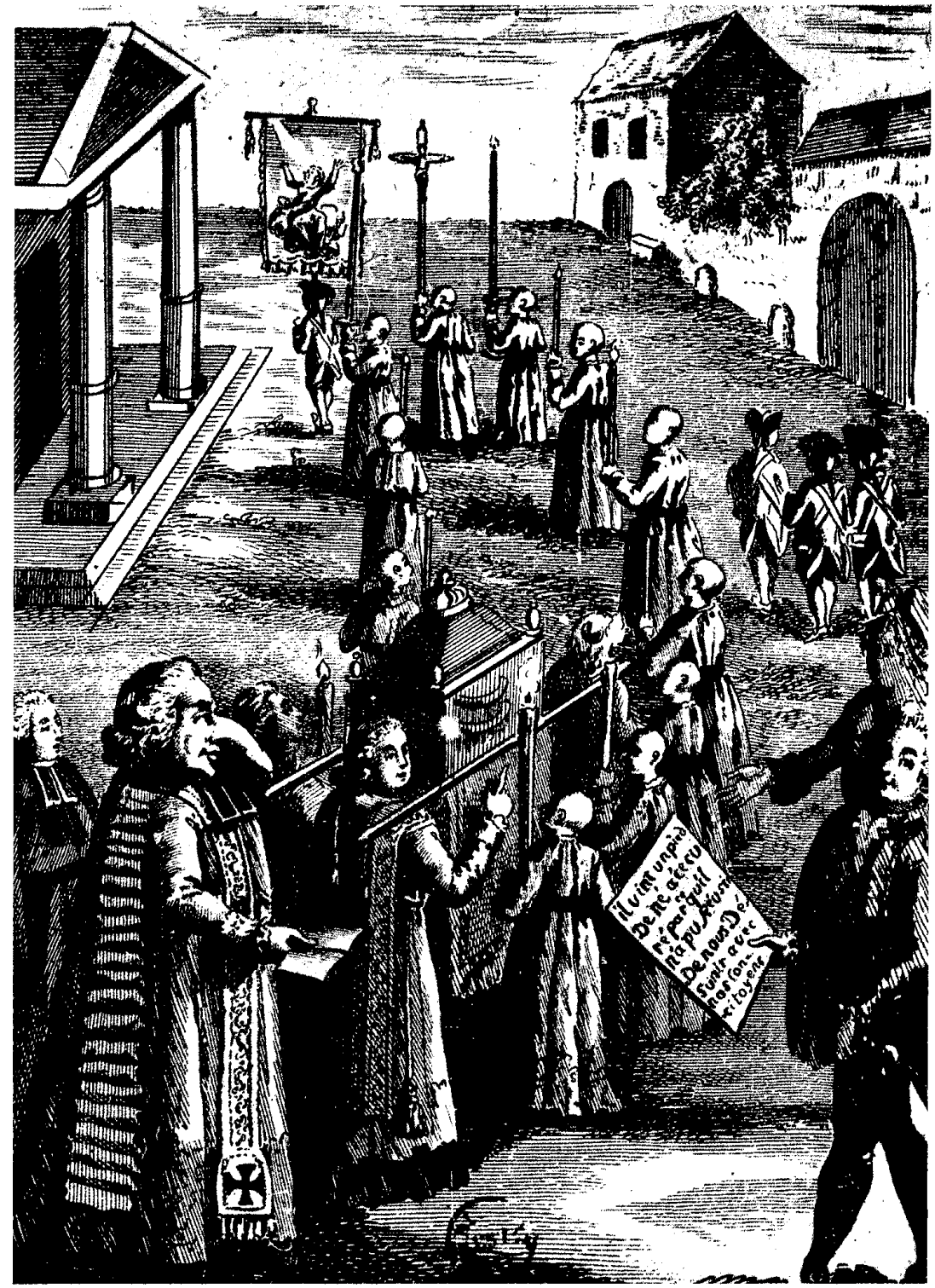

